\title{
From time to time. A constructivist approach to sociality in learning
}

\section{Mancini, Francesco ${ }^{a}$ and Glusac, Tanja ${ }^{b}$}

${ }^{a}$ Department of Architecture, Curtin University, Western Australia, ${ }^{b}$ Department of Architecture, Curtin University, Western Australia.

\begin{abstract}
Under the current financial pressures, tertiary education increasingly looks towards corporate sector to import its model of management and efficiency. While benefits of this model can be seen in practice, in regard to staff and facilities management and financial viability, its impact on teaching and learning is causing a disruption to the very core of tertiary education, eroding sociality in learning and opportunities for sharing knowledge and values. Capacity to work in teams and ability to critically solve problems by collaborating and sharing insights and information, are skills students are expected to gain during their studies. The development of these skills to their fullest using Design Thinking approach, however, is currently not widely supported, albeit desirable, ${ }^{l}$ in the present education context which is addressing the efficiency of time management by reducing contact time, increasing student/staff ratio and shifting towards integrated and mass education modes of delivery. While this paper is not disputing the existing model, it responds to its current challenges proposing a stronger integration of different factors contributing to learning. The aim is to present a collaborative working model as a way of bridging 'the missing link between theoretical findings [on holistic and interdisciplinary learning] and demands by pedagogy science, ${ }^{2}$. Such a model is envisioned to encourage sociality in learning and strategize spaceltimelexperience management, ultimately enhancing knowledge and value sharing.
\end{abstract}

Keywords: Design Thinking; Constructivism; experiential Learning; Sociality; Studio Culture.

\footnotetext{
1 Ability to solve 'wicked problems' as supported by Design Thinks is becoming more attractive to the tertiary sector as it promotes 'holistic modes of constructivist learning in projects' (Scheer et al. 2012, p. 8).

${ }^{2}$ Scheer et al. (2012, p. 8)
} 


\section{Introduction}

Approach to learning and teaching from a Humanistic perspective is often seen to be holistic. This approach is based on constructivism, an epistemological model which 'describes the individual human subject engaging with objects in the world and making sense of them' (Crotty, 1998, p. 79). This making sense, or creating meanings, is aided by 'the mélange of cultures and sub-cultures into which we are born' (Crotty, 1998, p. 79). Cultures, by definition constructs themselves, are dynamic and ever changing. Learning and knowledge in this context is equally ever evolving and expanding 'through new insights' and 'individual experiences' (Scheer et al. 2012, p. 9 drawing form Reich (2008) and Kolb (1984)) In this regard, the culture of learning and sociality traditionally fostered within educational institutions, such as universities, is seen as essential. Nevertheless, this holistic approach to education, including the culture of building sociality of learning, is being challenged by constant time and resources cuts brought about by financial pressures and adoption of a corporate model of management and efficiency within tertiary education sector.

As a response to these pressures and cuts, this paper looks at the problem of time loss and consequential loss in sociality, and proposes to tackle it from the Design Thinking perspective. Design Thinking has been selected as a methodology to counteract and solve the above indicated complex problems due to its primary focus being on value as an end product or service. This paper argues that Design Thinking can be introduced to wider areas where it equally can be used as a methodology for tackling various pedagogical problems and achieving constructivist type of learning, due to particular skill set that it helps develop as suggested by Razzouk and Shute (2012, p. 331). It is for this reason that Design Thinking is slowly making its way into a variety of disciplines, including Business which uses Design Thinking to look at innovative strategies for problem solving. According to Kees Dorst (2011, p. 522 drawing from Stacey, Griffin and Shaw 2000) 'the business and management communities' are introducing Design Thinking in their practices to 'broaden their repertoire of strategies for addressing the complex and open-ended challenges faced by contemporary organisations'. Gaining meta competences required of the $21^{\text {st }}$ century learners that extend 'beyond cognitive knowledge' is the complex and open-ended challenge facing education sector, specifically universities, which, according to Scheer et al. (2012, p. 8), is possible to achieve 'with the help of constructivist learning'.

\section{Problem}

Under the current financial pressures, tertiary education increasingly looks towards corporate sector to import its model of management and efficiency. While many benefits of this model can be seen in practice, in regard to staff and facilities management and financial 
viability, its impact on teaching and learning is causing a disruption to the very core of tertiary education, eroding sociality in learning and opportunity for sharing knowledge and values.

The current corporate model, fast entering academia, has been identified by Richard Sennett (2005) as a new stage in capitalism striving for 'flexibility'. Sennett (2005, p. 113) suggests that this post-Fordist model has been brought about by 'the globalization of labor and capital flows' as well as 'a transformation in production' which consequently altered existing organizational structures and their bureaucratic systems with the goal of increasing flexibility in the work environment. A deviation from a Weberian model of 'the bureaucratic triangle ${ }^{3}$ to the post-Fordist model currently in place caused the 'de-layer[ing]' of organizations with the aim of substituting excessive 'levels of bureaucracy' with the fast evolving information technologies (Sennett 2005, pp. 113, 114). Sennett (2005, p. 114) suggests that through this 'de-layer[ing]', businesses 'sought to destroy the practice of fixedfunction work', which was seen to be too rigid and unresponsive to the prevailing fast changing market conditions. Within this model, companies are opting to reorganize themselves as internal markets generating internal competition with the aim of achieving greater effectiveness and efficacy. Though businesses are slowly sobering up to the reality of this model and its many short-comings ${ }^{4}$, universities, which are not suited to this model, seem to be dragging their feet.

The post-Fordist award-based system driven by Key Performance Indexes and consumerist and service oriented mentality, that has gradually permeated tertiary sector, does not apply well to educational settings since it leads to the loss of the 'real' motivators that are research and investment in teaching. This loss, in what is effectively the backbone and essence of tertiary educational institutions, is indirectly leading to the loss of efficiency and productivity on academics' part who are becoming increasingly burdened by bureaucratic and administrative tasks which the post-Fordist model tried to minimize.

This disruptive model that we have been facing for some time has been extensively discussed and critiqued by Maggie Berg and Barbara K. Seeber in their book titled The Slow Professor: Challenging the Culture of Speed in the Academy. Both professors in the

\footnotetext{
3 Sennett (2005, p. 114) suggests that Max Weber's (1922) notion of 'rational bureaucracy was founded on an analogy between military and business organization' with both having clearly identified and strictly hierarchical chain of command. Though initially associated with military and industry, since 1960s Weber's model penetrated the white-collar sector, including universities.

4 According to Sennett (2005, p. 115), 'just as the space of power in the flexible organization is not democratic, so the time dimension of these institutions promotes neither loyalty nor fraternity. Business leaders who were once enthusiasts for constant corporation reinvention are beginning, as it were, to sober up. It is hard to feel committed to a corporation that has not defined character, hard to act loyally to an unstable institution that shows no loyalties to you. Lack of commitment translates into poor productivity, and to an unwillingness to keep a corporation's secretes.'
} 
Department of English at Queen's and Brock Universities respectively, they argue that 'If there is one sector of society that should be cultivating deep thought in itself and others, it is academia. Yet the corporatization of the contemporary university has sped up the clock, demanding increased speed and efficiency from faculty regardless of the consequences for education and scholarship' (Berg and Seeber 2016, cover sheet). More specifically, some of the 'on the ground' problems related to time cuts affecting both academics and students across Australian universities are:

- Inflexibility of and compliance with the curriculum has led to a disproportionately high imbalance in terms of time required to complete menial administrative tasks and time dedicated to teaching, research and preparation. This imbalance is contributing to the lack of innovation, and academics embracing the risk adverse culture by opting for 'the safe way' due to limited for experimentation in teaching.

- The reduction in contact hours has resulted in compressed delivery and focus on content packaging with limited opportunities to explore the depth and breadth of content and contextualization. This reduction in contact hours and increased offering of lectures online has also led to an unhealthy perception that attending classes is not important or worth students' time consequently contributing to fewer interaction opportunities with staff and with other students.

- Students are often too focused on delivery and production of assessment tasks. This is done mostly at the expense of deep research and learning. This attitude, when coupled with the ever decreasing time available to academics to assess students' work, is increasingly impacting on the extent and quality of feedback, which is then elevating risk of jeopardizing fairness.

- Fragmentation of time due to constant flow of emails and social media distractions. From the students' perspective there are also other commitments outside university such as employment, often full-time, necessary to cover tuition fees and livelihood expanses, and the need for a balanced social life.

- Extended response time to requests for information/administrative responsibilities, and administrative imbalance between responsibility and authority.

The above listed issues stemming from the reduction of time inadvertently lead to fragmentation of 'Knowledge acquisition', focus on 'isolated subjects' and inability to 'execute a holistic and interdisciplinary learning' that are starting to negatively affect the overall experience of both teachers and students (Scheer et al. 2012, p. 8). In this process, many valuable opportunities to reflect and identify connections and form a 'big picture' are lost. While these conditions are necessary to acknowledge and contemplate upon, since they are here to stay at least for a foreseeable future, they are also raising a sense of urgency 
for educators and academics to re-evaluate their current approach to teaching and research as a way of responding to the pressures imposed by the post-Fordist corporate model. As a way forward, this paper proposes an alternative approach addressing the problems academia is facing in the teaching arena by using constructivist framework and Design Thinking methodology.

\section{Pivot point}

Capacity to work in teams and ability to solve problems by collaborating and sharing insights and information, including critical thinking, are skills students are expected to gain during their studies. Dunne and Martin (2006, p. 519) suggest that 'An important aspect of collaboration, however, is the idea of expanding perspectives by collaborating with individuals unlike oneself.' One of the ways of achieving this is through utilizing Design Thinking methodology.

So what is Design Thinking? Tim Brown (2008, p. 1) defines Design Thinking as 'a methodology that imbues the full spectrum of innovation activities with a human-centered design ethos.' He further suggests 'that innovation is powered by a thorough understanding, through direct observation, of what people want and need' (Brown 2008, p. 1). Central to Design Thinking is a reasoning process referred to as Abduction, which, according to Dorst (2011, p. 523-524) can be approached from two angles - Abduction-1 which considers 'conventional problem solving' where the value and the working principle are given but the 'what' is unknown, and Abduction 2 - where only the end value is known, but the 'what' and the 'how' are missing. These are summed up by Dorst (2011, p. 524) in the following formula redrawn by authors:

$\begin{array}{lccccc}\text { Abduction } & \text { WHAT } & +\quad \text { HOW } & \text { leads to } & \text { VALUE } \\ & \text { (thing) } & & \text { (working principle) } & & \text { (aspired) } \\ \text { Abduction-1 } & ? ? ? & + & \text { HOW } & \text { leads to } & \text { VALUE } \\ \text { Abduction-2 } & \begin{array}{c}\text { ??? } \\ \text { (thing) }\end{array} & \text { (working principle) } & & \text { leads to } & \text { VALUE } \\ & & & & \text { HOW } & \text { (aspired) }\end{array}$

Dorst (2011, p. 525) suggests that to effectively investigate such a problem it is essential to apply a reverse engineering process by taking into account the known outcome, which is the desired value, and work iteratively on possible frameworks to identify what needs to be designed. The aim is to further reduce the level of complexity of the problem by figuring 
From time to time. A constructivist approach to sociality in learning.

out how the designed object will fulfil the set of given values so to successfully complete the equation. According to Dunne and Martin (2006), this is where the ethos becomes important, in the moment when the designer and the customer/client set a shared reference value against which complete equations can be tested out of a range of possible solutions (Dorst 2011, p. 525). According to Charles Owen (2007) Design disciplines belong to a synthetic/real realm (fig.1 adapted from Owen 2007).

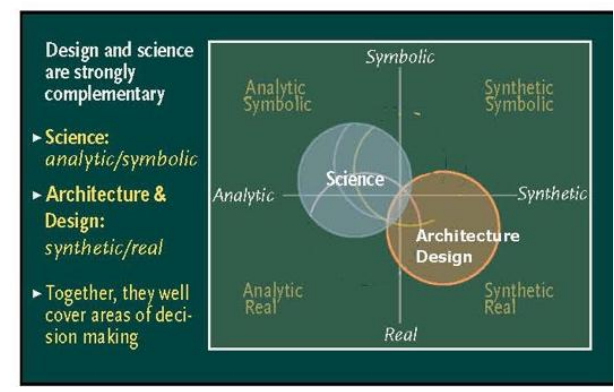

Figure 1. (adapted from Owen, 2007) Design and Science are Complementary

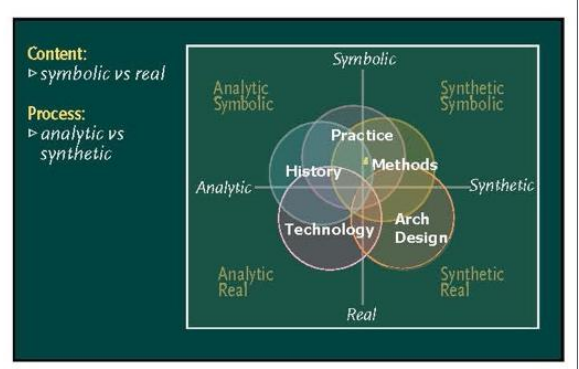

Figure 2. (adapted from Owen, 2007) Differences within Architecture Design, Technology, Practice, History and Theory. Methods of Communications can be compared to owen's positioning of Design, Medicin, Science, Art and Law

After identifying in detail the components of a creative character (Table: 1 from Owen 2007), 
Table 1. Creative skills according to Charles Owen (adapted from Owen, 2007, p22-23)

\begin{tabular}{|c|c|c|}
\hline Fabun's List - The talented writer & Silvano Arieti - psycho aatitudes & Csikszentmihalyi's - emotional Polarities \\
\hline $\begin{array}{l}\text { Sesitivity. Ability to see and to respond } \\
\text { Questioning attitude. Inquisitiveness, } \\
\text { encorages seeking new and original answers. } \\
\text { Board education } \\
\text { Asymmetrical thinking } \\
\text { Personal courage } \\
\text { Sustained curiosity } \\
\text { Time control } \\
\text { Dedication } \\
\text { Willingness to work }\end{array}$ & $\begin{array}{l}\text { Fluency of thinking } \\
\text { Flexibility } \\
\text { Originality } \\
\text { Redefinition } \\
\text { Elaboration } \\
\text { Tolerance for ambiguity }\end{array}$ & $\begin{array}{l}\text { Generalized libidinal energy and restraint } \\
\text { Convergent and divergent thinking } \\
\text { Playfulness and discipline - or irresponsibility } \\
\text { and responsibility } \\
\text { Fantasy and reality } \\
\text { Extroversion and introversion } \\
\text { Humility and pride }\end{array}$ \\
\hline
\end{tabular}

Owen asserts that albeit creativity is common to both Science Thinking and Design Thinking, the former is fundamentally initiated by analysis of facts, while the latter includes facts and possibilities since the beginning as part of an open-ended problem which needs a real response, a form. In addition to that, Owen demonstrates that Design Thinking is a particular creative approach to problem solving, as it is based on peculiar metacognitive skills (Table 2, adapted from Owen, 2007) which make a fundamental difference with any creative process in scientific realm.

Table 2. Design thinking metacognitive skills adapted from Owen 2007, p22-23)

\begin{tabular}{|l|l|l|}
\hline Non-io Centered concern & $\begin{array}{l}\text { Communication with self and others as a way } \\
\text { of designing }\end{array}$ & $\begin{array}{l}\text { Open ended solution trajectory or context } \\
\text { relevance in relation to goal (form) }\end{array}$ \\
\hline $\begin{array}{l}\text { Conditioned inventiveness } \\
\text { Human-centered focus } \\
\text { Enviroment-centered concern }\end{array}$ & $\begin{array}{l}\text { Ability to visualize } \\
\text { Tempered optimism } \\
\text { Bias for adaptivity }\end{array}$ & $\begin{array}{l}\text { Predisposition toward multifunctionality } \\
\text { Systemic Vision } \\
\text { View of the Generalist } \\
\text { Ability to work systematically with qualitative } \\
\text { information }\end{array}$ \\
Self-governing practicality & $\begin{array}{l}\text { Ability to use language as tool } \\
\text { Affinity for teamwork }\end{array}$ & \\
\hline
\end{tabular}

While Science values the correctness of conclusions using a false/true matrix, in Design the assessment of a solution to an open ended problem is made considering the effectiveness of that solution among multiple credible solutions on the base of a set of cultural values (Owen, 2007, pp. 22-25). This conclusion is inherent to a number of criteria which shape the common ground of any design discipline. Their ultimate goal is giving form to products, artifacts and environments which constitute the language of human individuals for their coexistence in social communities. As a consequence of this intricate relation, Design problems, as well as designers, are informed by the same anthropological, social, artistic, legal-economic and technological implications which generate the complex open ended problems that they are called to solve. In the learning environment, this means that Design Thinking is sympathetic with constructivism and 'gets teachers empowered to facilitate constructivist learning' (Scheer et al. 2012, p. 8)

Presented next is a collaborative working model based on Design Thinking that not only contests the assumption that Design Thinking is less time efficient due to being an iterative process, but also encourages sociality in learning and strategize space/time/experience management, thus ultimately enhancing knowledge and value sharing. 


\section{A Design Thinking based teaching model: Studio 144}

The proposed teaching model for Design disciplines based on Design Thinking and Constructivism rests on the assumption that both share common principles of critical inquiry, as outlined by Crotty (1998, p. 157) in that they both assume that facts cannot be seen outside their value and ideological context. Concepts, likewise, are always to be filtered through power and social relations rooted in history. From this it follows, that the relationship between the two is always mediated within the realm of social relations, such as production and consumption, and therefore language.

With this in mind, the proposed constructivist model tries to realize a teaching environment which facilitates the gaining of the Design Thinking metacognitive competences presented by Owen (2007) and illustrated in table 2. In this model, problems, facts and a set of cultural values are presented to students for them to elaborate further while developing the competences skillset described in table 2 that are grouped in three sets of values 1) non-ego centric design concern, 2) communication with self and others as a design tool, 3) open ended solution trajectory. Such a teaching model advocates for a careful simulation of external conditions and stakeholders contribution. This model can then take advantage of a continuum of space/time flow and hands on strategy which is no longer broken down into hierarchically assigned micro tasks as happens under the Fordist/Taylorist approach.

More specifically concerning Architecture, Studio culture, which has been a prevalent model since Bauhaus, has been progressively dismissed by universities due to increasing cost associated with running studio based teaching. In the traditional studio model a space is set aside for students to spend time there throughout a week within and outside teaching hours. Willing to consider a student centered learning approach the aim is to set a 'new' multi- purpose studio space where students can work and attend lectures, seminars and workshops for all the subjects taught during the semester and not just Architectural Design. Correspondingly, and drawing from Owens (2007), the Design Thinking strategies can be applied to the five core subject areas of Architecture course, including Design, Methods of communication and inquiry, History and Theory, Technology and Professional Practice. The point of deviation from a typical model concerned with teaching facts and delivering content is the emphasis on teaching subject values first and foremost. The consequential interpretation of facts based on a set of values according to a creative thinking investigation helps to shape the measures necessary to solve a design problem in Architecture and to apply it in practice (fig 3 adapted from figure 9 Owen 2007, p. 21). 


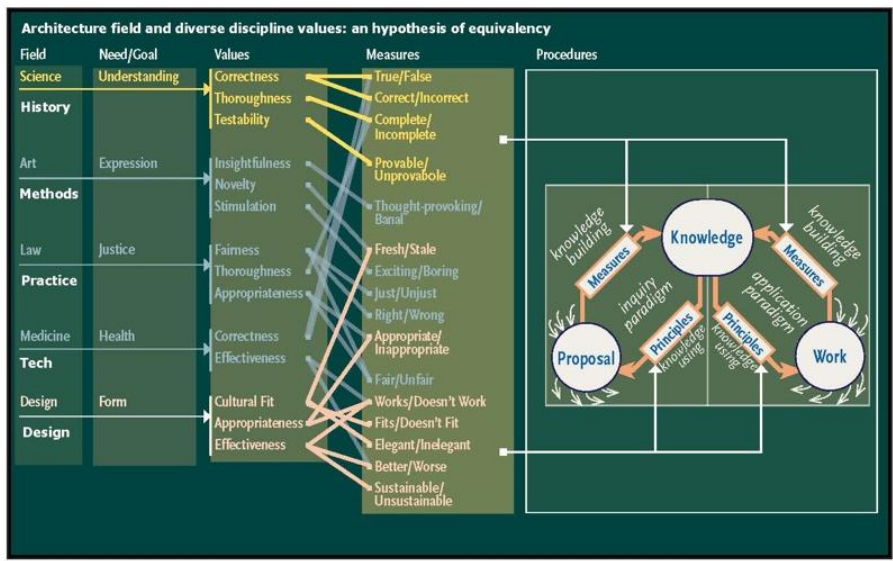

Figure 3. (adapted from Owen, 2007) hypothesis of equivalence of values between disciplines and architecture subjects

In order to generate this condition, not only the program, but also space and time need to be carefully considered and planned in tune with the teaching model, as the time spent together helps you take ownership of the place and the experience, and inadvertently learning. If the responsibility is taken for the space, it can be associated with responsibilities inherent to the learning activities of students in such spaces. (Hertzberger, 2009, p. 28).

In conclusion, this model based on problem solving can be proven to be effective and exportable to other disciplines. Notwithstanding our faith in its usefulness, we believe that such model should not substitute, but integrate the present task based model, as we believe that it is worth to expose students to various learning experiences to widen their adaptability and their skillset.

According to Crotty $(1998,79)$ 'we are taught and we learn in a complex and subtle process of acculturation. ... Our cultural heritage can therefore be seen as a pre-empting task of meaning making so that [today] for the most part we simply do not do what constructivism describes as doing.' While this indeed may be the case, the constructivist approach allows for continuous criticism of former meaning making space for further insights and deepening of the existing, and at the same time providing opportunities for new meanings to be created (innovation). To this end, understanding in which moment of students' education it is worth to apply this model and how often in the curriculum remains an open ended problem for discussion. 
From time to time. A constructivist approach to sociality in learning.

\section{References}

Beckman, S. L., \& Barry, M. (2007). Innovation as a Learning Process: Embedding Design Thinking. California Management Review, 50(1), 25- 56.

Brown, T. (2008). Design Thinking. Harvard Business Review, June. 1-9. Reprint R0806E.

Buchanan, R. (1992). Wicked Problems in Design Thinking. Design Issues, 8(2), 5-21. http://www.jstor.org/stable/1511637

Crowther, P. (2013). Understanding the signature pedagogy of the design studio and the opportunities for its technological enhancement. Journal of Learning Design. Special Issues: Design Education, 6(3), 8-28.

Dorst, K. (2011). The core of 'design thinking' and its application. Design Studies, 32, 521.532. DOI:10.1016/j.destud.2011.07.006

Dunne, D., \& Martin, R. (2006). Design Thinking and How It Will Change Management Education: An Interview and Discussion. Academy of Management Learning \& Education, 5(4), 512-523. http://www.jstor.org/stable/40214410

Hertzberger, H. (2009). Lessons for Students in Architecture. Rotterdam, Netherlands: 010 Publishers.

Owen, C. (2007). Design Thinking: Note on its Nature and Use. Design Research Quarterly, 2(1), 16-27.

Razzouk, R., \& Shute, V. (2012). What Is Design Thinking and Why Is It Important? Review of Educational Research, 82(3), 330-348. DOI:10.3102/0034654312457429

Scheer, A., Noweski, C., \& Meinel, C. (2012). Transforming Constructivist Learning into Action: Design Thinking in education. Design and Technology Education: An International Journal, 17(3), 8-19.

Sennett, R. (2005). Capitalism and the City: Globalization, Flexibility and indifference. In Y. Kazepov (Ed.), Cities of Europe. Changing contexts, local arrangements, and the challenge to urban cohesion (109-122). Oxford, England: Blackwell Publishing. 